\title{
Políticas Públicas para Adolescentes em Vulnerabilidade Social: Abrigo e Provisoriedade
}

Public policies for adolescents in social vulnerability: Sheltering and provisory nature

Ana Paula

Granzotto de Oliveira \& Clary Milnitsky-Sapiro

Universidade Federal do Rio Grande do Sul

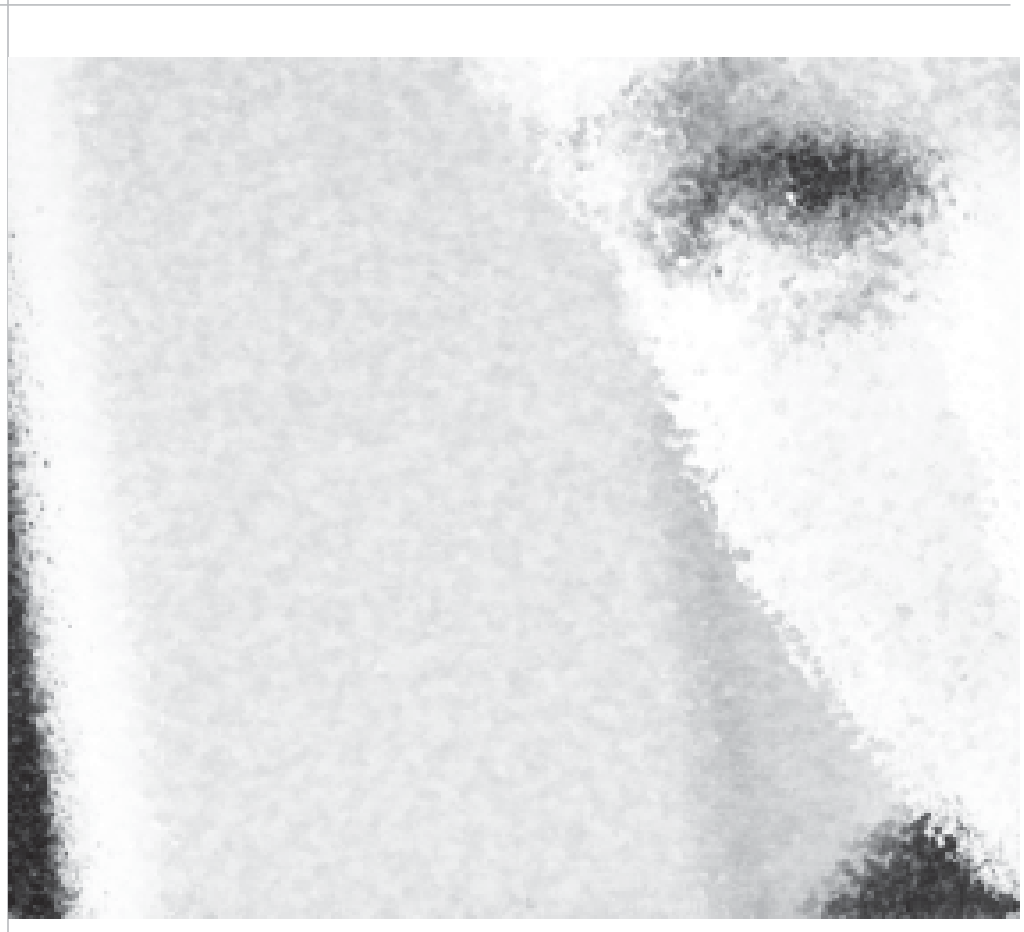




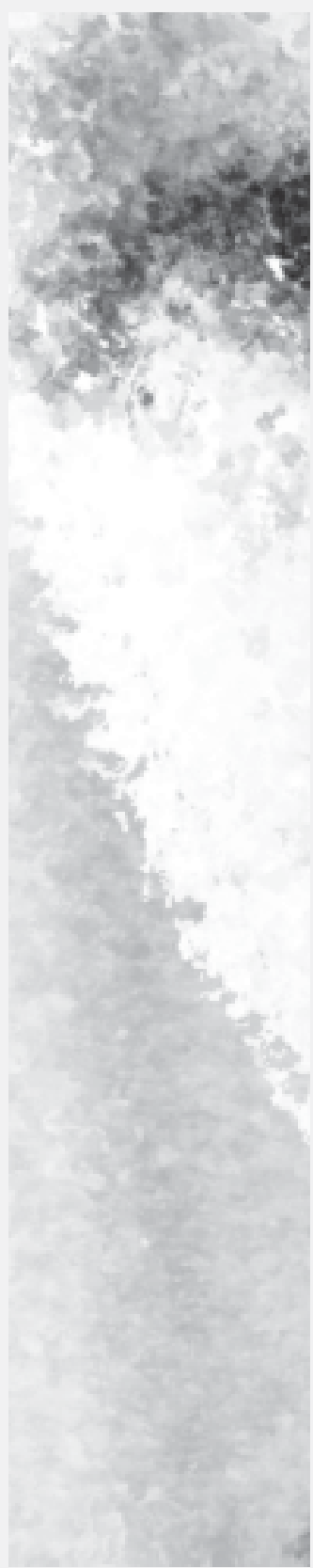

Resumo: O presente artigo é resultado de uma pesquisa de mestrado realizada em duas instituições de abrigo para adolescentes no Município de Porto Alegre, RS - uma governamental e uma ONG - e teve por objetivo analisar as práticas cotidianas e a estrutura física de cada instituição, visando a identificar possíveis diversidades entre esses elementos. Além de investigar diferenças, o artigo traz uma reflexão crítica acerca das políticas públicas na área de abrigo e acolhimento de adolescentes em situação de vulnerabilidade social. Através da análise do conteúdo das falas de adultos e adolescentes participantes, procurouse descrever o quanto políticas macro e micro interferem no acolhimento oferecido. Enfatizou-se a complexa relação entre o caráter provisório da medida de proteção, preconizada pelo ECA, e a importância do vínculo entre cuidadores e abrigados para um trabalho de integração social que vise à ressignificação das histórias de vida dos adolescentes.

Palavras-chave: políticas públicas, ECA, abrigo, adolescentes.

Abstract: This paper is the outcome of a master's degree research project developed within two sheltering institutions for adolescents in the city of Porto Alegre-RS, Brazil - one governmental and the other nongovernmental (NGO) - that analyzes both the daily practices and the premises of these institutions as a means to identify possible differences between the shelters. Additionally, this paper raises a number of relevant questions about public policies when applied to sheltering adolescents in a socially vulnerable situation, as a means of fomenting future discussions. Through the content analysis of the narratives of interviewed adults and adolescents, this paper describes how macro and micro policies interfere in the services offered, and emphasizes the complex relationship between the provisory nature of the protection measures, as praised by ECA (Child and Adolescent Statute), and the importance of bonds between the caregivers and the sheltered as a means of permitting the resignification of the sheltered life stories.

Key words: public policies, ECA, sheltering, adolescents.

Entre os anos 30 e final dos anos 70, o Brasil constrói um sistema de políticas sociais no qual o investimento social do Estado é de grande importância, porém, apesar do esforço, o desempenho das políticas sociais fica aquém das necessidades da população. É só a partir de meados dos anos 70 que o problema popularmente conhecido como menor abandonado (termo de conotação pejorativa) passa a ser assunto presente e foco crescente de atenção. "Palavra de ordem na época, sobretudo nos primeiros anos da década de 80, refletia a necessidade de revelar a [...] verdadeira situação em que se encontravam as crianças provenientes das camadas pobres e miseráveis da população” (Rizzini, 1996, p.70).

O objetivo deste artigo é refletir acerca das políticas públicas para a área de abrigagem,
Os termos "abrigagem" $e$ "abrigamento" utilizados ao longo do texto são empregados pelos profissionais que trabalham na área da infância $e$ juventude, especialmente com equipamentos da rede de proteção - dentre eles os abrigos. Estes termos, na grande maioria das vezes, buscam trazer a idéia de processo, de dinamicidade e de uma nova metodologia de trabalho. 
especialmente no que se refere ao abrigamentode adolescentes e à provisoriedade da medida. A partir da definição do problema dessa pesquisa, optou-se por uma metodologia qualitativa, de caráter descritivo. Dentre os métodos qualitativos, a descrição de cunho etnográfico (Milnitsky-Sapiro, 2005) caracterizou-se como imprescindível, visto que se buscou mais que uma entrada no campo

"... o termo política pública "compreende a dimensão éticopolítica dos fins da ação, e deve se aliar, necessariamente, a um projeto de desenvolvimento econômico-social e implicar formas de relação do Estado com a sociedade".

Sposito de investigação: conhecer recortes do cotidiano do grupo pesquisado e identificar o contexto.

A pesquisa que originou esse artigo aponta uma visível necessidade de implementar políticas públicas para a juventude na sociedade brasileira contemporânea, devido à ausência de programas sociais que acolham esse segmento social. Segundo Sposito (2003b), o termo política pública “compreende a dimensão éticopolítica dos fins da ação, e deve se aliar, necessariamente, a um projeto de desenvolvimento econômico-social e implicar formas de relação do Estado com a sociedade”(p.59).

Alguns estudos sociodemográficos no Brasil destacam que, notadamente após a segunda metade da década de 1990, ocorre um significativo aumento da população jovem, que constitui cerca de $20 \%$ da população brasileira. Com isso, algumas ações específicas, destinadas à juventude, passam a ser implementadas, segundo Oliveira (2001)”.

Em 1995, o número de jovens entre 20 a 24 anos atingiu um contingente de 13 milhões de indivíduos, o equivalente a 8,5\% da população total do País. (...) Adolescentes de 15 a 19 anos somavam 15,7 milhões de pessoas, ou 10,4\% da população geral. Como resultado, vivemos em 2000 um inédito pico demográfico do número de adolescentes, calculado em cerca de 50 milhões na faixa etária de 10 a 24 anos. Mais do que isso: entramos no novo século com a maior população juvenil da história demográfica brasileira ( Oliveira, 2001,p.54). Apesar do expressivo número de indivíduos que compõem a população juvenil brasileira, há ainda um importante caminho a ser trilhado no que diz respeito à elaboração, implementação e avaliação de políticas públicas para essa população, especialmente no que se refere ao reconhecimento do lugar do adolescente na sociedade para a elaboração de programas de políticas públicas que incluam a produção acadêmica além da técnica, nesse processo. Muitos estudos são necessários a fim de compreender como as ações destinadas aos jovens são gestadas e sob que lógica elas funcionam. Buscou-se explicitar que tal lógica apresenta um caráter de “compensação provisória”, e relega a um segundo plano a integração social a longo prazo. Nesse sentido, as autoras concordam com a afirmação de Sposito (2003b), que define serem as políticas públicas destinadas para a juventude e sua análise, certamente, revestidas de provisoriedade.

Com relação a que lógica obedece a concepção das políticas públicas para a juventude, Abad (2002) in Sposito (2003), afirma que a evolução das políticas de juventude na América Latina foi determinada "pelos problemas de exclusão dos jovens da sociedade" e pelos “desafios de como facilitarlhes processos de transição e integração ao mundo adulto”. Esse autor resume alguns aportes de vários outros autores e elabora uma periodização em torno de quatro modelos diferentes de políticas para a juventude: “a ampliação da educação e uso do tempo livre (entre 1950 e 1980)”, “o controle social de setores juvenis mobilizados (entre 1970 e 1985)“, “o enfrentamento da pobreza e a prevenção do delito (entre 1985 e 2000)” e "a inserção laboral de jovens excluídos (entre 1990 e 2000)” (p.3).

A Constituição de 1988 passa a regular importantes princípios de reestruturação do sistema brasileiro de políticas sociais, dentre eles, uma ampliação e extensão dos direitos sociais. Ocorre, porém, que esses direitos 
ficam "no papel”, pois não há como colocálos em prática, uma vez que as políticas públicas também vivem um momento de reformulação, intensificado com a agenda do governo Fernando Henrique Cardoso, a partir de 1993.

No período que vai de 1995 a 2002, segundo Sposito (2003), as iniciativas federais na área social foram demasiadamente pequenas, se comparadas a outros programas e projetos governamentais. Já no período que vai de 1999 a 2002, são implementados 18 novos programas, número fecundo quando comparado ao período anterior. O que se constata, nesse último período, é um aumento significativo referente à temática dos adolescentes e jovens no âmbito do governo federal.

No entanto, o que se percebe do período é que o que foi herdado desse governo se restringiu a uma série de "projetos isolados e sem avaliação, configurando a inexistência de um desenho institucional mínimo que assegure algum tipo de unidade, que nos permita dizer que caminhamos na direção da consolidação de políticas e formas democráticas de gestão”(Sposito, 2003, p.15).

Não é de surpreender que o ECA tenha surgido justamente nesse contexto de expansão da democracia social, pós-regime militar, e de participação social, voltado para os direitos sociais, neste caso, direitos das crianças e dos adolescentes.

O Estatuto da Criança e do Adolescente (ECA) é uma Lei Federal (n ${ }^{\circ}$ 8.069), promulgada em 13 de julho de 1990, que se caracterizou como expressão máxima do desejo da sociedade brasileira de garantir direitos a crianças e adolescentes historicamente fragilizados, principalmente os provenientes de classes sociais menos favorecidas. O ECA constitui o marco legal de um processo práticoreflexivo referente a políticas públicas para a infância e adolescência, um instrumento norteador de novos paradigmas no atendimento e atenção a crianças e adolescentes em estado de abandono social ou prestes a ingressarem nessa situação.

Fonseca (2004) adverte que a legislação que trata do bem-estar da criança e do adolescente "envolve muito mais do que valores humanitários consensuais. Longe de ser a conseqüência espontânea de uma preocupação objetiva, envolve filosofias, economias e negociações políticas que não devem ser subestimadas” (p.111). A autora chama a atenção para o viés que pode existir em qualquer documento, uma vez que este é, inevitavelmente, fadado a refletir os valores de sua época.

Desde sua publicação, no início da década de 90, o ECA enfatiza a reflexão fundada no paradigma da atenção e proteção integral à criança e ao adolescente enquanto sujeito de direitos. Refletir criticamente sobre esse novo paradigma e sobre esses direitos é um grande desafio, especialmente no contexto mundial, no qual muitos países, já na década de 80 , estavam reeditando sua legislação sobre o bem-estar da criança e do adolescente. Fazse ainda relevante observar que o ECA surgiu em um momento de "reabertura democrática, visando à promoção dos direitos sociais, econômicos e civis dos jovens" (Fonseca, 2004, p.104), ou seja, ao invés de simplesmente controlar os jovens, o ECA pretende garantir seus direitos.

Depois de entender o contexto em que surgiu o ECA e sua diretriz geral, faz-se importante destacar alguns pontos da política de atendimento - uma dentre as diversas diretrizes descritas no livro II, parte especial, título I - especialmente o que trata de entidades de atendimento (Capítulo II - Das Entidades de Atendimento). Os artigos 90 e 91 explicitam as disposições gerais sobre as entidades de atendimento, e o artigo $92^{1}$ trata
1Art. 92. As entidades que desenvolvam programas de abrigo deverão adotar os seguintes princípios: I preservação dos vínculos familiares; II - integração em família substituta, quando esgotados os recursos de manutenção na família de origem; III atendimento personalizado e em pequenos grupos; IV desenvolvimento de atividades em regime de co-educação; $V$ - nãodesmembramento do grupo de irmãos; VI - evitar, sempre que possível, a transferência para outras entidades de crianças e adolescentes abrigados; VII - participação na vida da comunidade local; VIII - preparação gradativa para o desligamento; IX participação de pessoas da comunidade no processo educativo. Parágrafo único. $O$ dirigente de entidade de abrigo é equiparado ao guardião, para todos os efeitos de direito." 
exclusivamente das "entidades que desenvolvam programas de abrigo”.

Ainda no capítulo II, observa-se uma descrição sobre as medidas específicas de proteção. Com relação à medida de proteção abrigo, o art.101 preconiza, em seu parágrafo único: “O abrigo é medida provisória e excepcional, utilizável como forma de transição para a colocação em família substituta, não implicando privação de liberdade".

O primeiro aspecto importante a ser ressaltado

"O abrigo é medida provisória e excepcional, utilizóvel como forma de transição para a colocação em familia substituta, não implicando privação de liberdade". no artigo 101 - parágrafo único - é referente à preconização de um tempo breve de permanência da criança e do adolescente em abrigo e busca contrapor-se a um passado recente, no qual estes passavam inúmeros anos isolados do mundo devido à institucionalização. O que se pode inferir é que esse parágrafo único, juntamente com o artigo 101, inciso VII (abrigo em entidade), além de identificar o caráter do programa, também delimita sua operacionalização.

De acordo com a pesquisa realizada pelo Instituto de Pesquisa e Economia Aplicada (IPEA/DISOC, 2003), a percentagem de abrigos da Rede SAC que seguem os princípios estabelecidos no artigo 92 do ECA mostra o quanto ainda é baixa a percentagem de alguns destes. Os três princípios relevantes para esta pesquisa possuem a seguinte percentagem: (iii) atendimento personalizado e em pequenos grupos, 10,5\%; (iv) não desmembramento de grupos de irmãos, 5,3\%, e (vii) evitar, sempre que possível, a transferência para outras entidades de crianças e adolescentes abrigados, $0,2 \%$.

Alguns aspectos que foram observados no transcorrer da pesquisa, no que se refere às políticas públicas voltadas para a área de abrigo e o acolhimento de adolescentes, serão analisadas abaixo. Inicialmente, faz-se importante mencionar o atravessamento das diversas instâncias que marcam o percurso dos adolescentes abrigados. Estas envolvem tanto as justificativas para o abrigo, os indivíduos e as instituições autorizadas a determinarem essa medida quanto quais instituições irão acolher o adolescente que será abrigado. Todo esse percurso traz, subjacente, o princípio de transitoriedade, que promove diferentes níveis de "res" e "desresponsabilização" entre atores e agentes (Oliveira; Milnitsky-Sapiro, 2006).

Muitos são os fatores que permeiam a experiência do adolescente quando este necessita morar em um abrigo. O princípio da transitoriedade, ou 'provisoriedade', é o principal deles, por envolver questões delicadas e complexas e, especialmente, por contraporse a uma história de institucionalização, na qual crianças e adolescentes viviam longos anos dentro de um abrigo (Rizzini, 1996). A transitoriedade é justificada pela lei através da provisoriedade da medida, pela qual se entende que crianças e adolescentes não deveriam permanecer em um abrigo por muito tempo. Por outro lado, a transitoriedade é experienciada pelos adolescentes muitas vezes de maneira totalmente diferente do que propõe, idealmente, a questão da provisoriedade da medida, e acontece por motivos diversos, como veremos a seguir.

Na instituição Renascer, por exemplo, existe um documento detalhando as situações que justificam uma transferência. Já na instituição Recriar, a justificativa para uma transferência é encontrada no reordenamento da instituição, na qual um modelo de atendimento, pautado na idade e gênero dos abrigados, determina sua localização no futuro. Dessa forma, constata-se primeiramente ser a provisoriedade não apenas sinônimo de um 'breve período abrigado', mas sim, uma justificativa para possível rotatividade entre as unidades de uma instituição ou entre instituições.

Com isso, ouvimos, através das narrativas dos adolescentes da instituição Renascer, relatos de vivências que não traziam marcas de transferências de local de forma traumática, 
diferentemente das experiências dos adolescentes na instituição Recriar.

\section{Adolescente Ana (instituição Renascer, 12 anos):}

Não, não foi transferida, é por causa que a gente todas se mudaram.[...] Todas que estavam lá vieram pra cá. Como era muita gente, formou umas casinhas. Eram 25, nós...e a... o GB é... tá junto aqui também, o GB e o GA.

Adolescente Paulo (instituição Recriar, 15 anos):

Por causa dos cursos, que a T. ia me arrumar, um curso em uma escola técnica, daí ela me transferiu pra cá e aí ela falou que ia me arrumar um curso e até hoje eu tô esperando.......] Nada, a mesma coisa, só é um pouquinho mais diferente porque lá tinha cavalo, tinha onde trabalhar, movimentar o corpo, que aqui já não tem.

Uma outra constatação sobre a transitoriedade é a falta de clareza sobre os objetivos do abrigo por parte da família - comumente familiares requisitam vagas para os filhos em abrigos da mesma forma como solicitam vagas para uma escola. Por outro lado, essa falta de clareza também pode ser percebida no discurso dos adultos. No fragmento abaixo, pode-se observar que, quando o adulto fala sobre o abrigo e defende a provisoriedade da medida, este se refere apenas às crianças.

\section{Adulto Gilda (instituição Renascer, assistente social):}

Eu acho que eles têm isso como um orfanato, um corretivo... como quem vem pra cá e tem que ser corrigido...Tem muita mãe que acha que isso aqui é uma creche, tem tanta história de assistentes sociais que não sabem o que é um abrigo. Já vi várias pessoas dizendo que não sabem o que é um abrigo, né, na verdade, no estatuto, o abrigo está como medida de proteção e provisória [...]Um abrigo, pra mim, é uma medida provisória aonde, no momento, a criança tem que ser retirada e colocada, até pra ver a situação dela, porque que ela veio para o abrigo? Na verdade, eu verifico.

Um dos argumentos utilizados para questionar a transitoriedade diz respeito à importância da continuidade do acolhimento oferecido pelas instituições aos adolescentes abrigados. Alguns autores, como Winnicott (1999) e Santos (2004), já haviam apontado o quanto um atendimento com características como estabilidade ambiental e continuidade dos cuidados oferecidos é importante para o desenvolvimento emocional de crianças e adolescentes. Um ambiente capaz de proporcionar segurança e confiança possibilita ao adolescente experienciar um tempo singular e ressignificar, com o adulto cuidador, sua história de sofrimento e desesperança. Por outro lado, o receio de que o abrigo se torne algo permanente e, em oposição a um passado recente, onde abrigados eram isolados da comunidade indiscriminadamente, é justificado pela transitoriedade na lei, uma vez que evitaria a possibilidade de que isso ocorresse novamente. Muitos adultos cuidadores expressam esse receio.

\section{Adulto Mateus (instituição Recriar, monitor):}

Pela lei, tá ok, porque é a mesma instituição, o mesmo diretor, é a mesma... Pode não ser a mesma casa, mas pela lei tá, digamos assim. A... em Viamão, estavam separados os dois (querendo se referir a dois irmãos), um numa casa, e um na outra, mas era mais próximo, claro. [...] Os nossos meninos não, é algo, eles estão, muitos deles, já estão assim há muito, muito tempo, muitos anos, eles já estão viciados no abrigo, e isso é ruim. Por ser uma casa de passagem, não devia acontecer isso; claro que ninguém é fada madrinha, que estala os dedos e diz: "melhorou, a família melhorou; pode voltar pra casa”; eu vejo um crime pros meninos...
[...] Os nossos meninos não, é algo, eles estão, muitos deles, já estão assim há muito, muito tempo, muitos anos, eles já estão viciados no abrigo, eisso é ruim. Por ser uma casa de passagem, não devia acontecer isso; claro que ninguém é fada madrinha, que estala os dedos e diz: "melhorou, a familia melhorou; pode voltar pra casa"; eu vejo um crime pros meninos... 
Um ponto muito importante que pode ser destacado da fala desse adulto é a questão de o abrigo ser visto como uma 'casa de passagem' - dessa forma, constata-se um não entendimento de que a medida de abrigo é provisória, e não a modalidade (Carreirão, 2004), ou seja, alguns abrigos são destinados a acolher crianças e adolescentes com ínfimas possibilidades de retorno a curto prazo para a família. Essas instituições deveriam evitar transferências precipitadas de uma instituição para outra.

Um outro ponto que merece destaque é o quanto a abrigagem de adolescentes é algo complexo. Talvez se possa pensar que o tempo de demora possa ser proporcional ao tempo de saída do abrigo, ou seja, o retorno para casa. Contudo, a importância de sentirse pertencente a um lugar parece ser reconhecida por esse adulto cuidador, apesar de a idéia de se "ter uma referência" - se confundir com a idéia do abrigo - a de "levar o adolescente para o resto da vida”.

\section{Adulto Mateus (instituição Recriar, monitor)}

Não, eu usei. Eu usei, não é que tem uma Casa de Passagem, eu acho que é uma casa provisória, que bom se os meninos não ficassem muito tempo aqui, que bom que a situação deles em casa, ou que a situação deles... melhorasse e eles pudessem retornar ao ambiente familiar, mas eu acho que... a gente não pode dizer pra eles que eles estão numa casa de passagem, não pode, aqui é a casa deles no momento. Temos que trabalhar pra que esse momento, mas tem que se trabalhar pra que seja o mais curto possível. Por exemplo, o Júnior, ele tá apavorado porque vai ser desligado, porque o abrigo, pra ele, já é uma referência muito grande. É bom, claro, mas o abrigo não vai poder... levar o Júnior pro resto da vida; ele tem que caminhar... um pouco culpa nossa de ele ser acomodado, dado uma vida boa, pras crianças, confortável. Não que seja isso, mas eu acho que os meninos do abrigo permanecem muito tempo no abrigo.
A preocupação em não produzir uma dependência tanto do adolescente quanto de sua família com o abrigo e possibilitar a manutenção do vínculo familiar é outra justificativa para a transitoriedade. Por exemplo, segundo outro técnico, muitas famílias "esquecem" o adolescente no abrigo, muitas vezes, não indo visitá-lo, ou não buscando comunicação. Nesses casos, em conseqüência, o abrigo tem dificuldades para trabalhar o ambiente familiar com o objetivo de prepará-lo para receber novamente o adolescente. Atualmente tem-se observado uma mudança de abordagem com relação às visitas às famílias. Antes, as visitas eram condicionadas ao bom comportamento do adolescente durante a semana; agora, estas acontecem com mais freqüência, e procurase entender, dentro dos valores do adolescente, as possíveis causas para um "mau comportamento", ou seja, a relação entre "bom comportamento" e visita à família nos finais de semana está sendo repensada.

Adulto Gilda, assistente social:

Pra mim, o abrigo deveria ser provisório. Só que não acontece isso. A criança vem pra cá... o que é muito perigoso. Tem que continuar o vínculo familiar. Porque muitas vezes a família não procura ... tá lá, tá bem...aí tem que tá ligando, a gente tem que tá pedindo; tem situações assim ó; de que... tem crianças que ficam ... a gente tem exemplo assim dentro do abrigo de situações de crianças assim, de processos... não, tá o Judiciário também, tem todo um... demora, às vezes demora, e tudo, né? o próprio conselho traz, eu acho que... a demanda tão grande que ele acaba esquecendo, conselho traz...mas essa é situação mais do Judiciário, né? Eu trabalhei já com isso e vi questões de largar no abrigo e não visitar, na verdade eu acho que o conselho tem que participar também, seguir, né? Eu acho... tá faltando, assim... a gente... acompanha a família, mas eu acho que.. tem muita coisa falha, muita coisa falha, assim... tem 
que trabalhar com a geração de renda, eu acho... tudo é uma questão de desemprego, tá? quando a criança vem pra cá.

A complexidade em avaliar o comportamento de um adolescente como "bom" ou "mau" extravasa a manutenção dos vínculos familiares para interferir diretamente na transitoriedade: adolescentes que mostram "mau comportamento" costumam ser punidos com uma transferência (para outra unidade ou instituição).

\section{Adolescente Henrique (instituição Recriar, 15 anos):}

Já, mas não me lembro, não me lembro assim como é que era.[...] Em Porto Alegre. [...] Por causa...., por causa de uma briga, eu briguei lá e eles me mandaram pro DECA, e o DECA me mandou vim pra cá, pro Recriar.

Aqui, antes de mais nada, é importante salientar que as autoras não são defensoras do abrigamento prolongado e injustificado, mas acreditam na necessidade de que cada caso seja individualmente analisado, especialmente quando de trata de adolescentes. Como já relatado, o retorno de um adolescente abrigado para a família de origem é normalmente mais complexo do que o retorno de uma criança. Acrescenta-se ainda que a internação em um abrigo na adolescência ou pré-adolescência comumente envolve histórias de situação de rua, uso de substâncias psicoativas, prostituição e abuso. Essa história de uma permanência insustentável do adolescente no seu lar de referência como possibilidade ainda mais remota de retorno é claramente expressa por um dos técnicos:

Adulto Nádia, assistente social da instituição Renascer:

... É que depende também muito dos motivos de ingresso, não é, mas o adolescente assim, eu acho que o retorno dele pra família já é mais complicado, né? Então eu já não invisto tanto em família para o adolescente como se investe pra criança, né...[...] Porque se o adolescente ingressa, ele ingressa por uma situação extrema, né, ... porque senão ele sempre vai buscar alguém da família... um tio, uma tia, madrinha, avô, avó, não é? Então, se ele ingressa, é por uma situação extrema. Aí já fica muito difícil o retorno.

Adicionalmente, a ausência de políticas públicas adequadas também interfere em questões delicadas, como a separação de grupos de irmãos e o desligamento de adolescentes maiores de dezoito anos. Em relação à separação do grupo de irmãos, a crítica, muitas vezes, recai no próprio órgão responsável por fazer cumprir a garantia dos direitos das crianças e adolescentes: o Juizado da Infância e Juventude.

Adulto Luiz, monitor da instituição Renascer:

O próprio Juizado não cumpre. Uma das nossas meninas foi retirada daqui pra ir pra uma outra instituição, sendo que as duas irmãs dela estão aqui. A K., isso foi uma decisão dum juiz, porque, na cabeça dele, ela era a que teria mais possibilidade de ser adotada, ou seja, a que venderia mais rápido... a mercadoria mais bonitinha ... então leva pra outro lugar. É o juiz da Vara da Infância e da Juventude, não é qualquer juiz. Não é um juiz alheio ao conhecimento do Estatuto, ao conhecimento da rotina do trabalho, ao trabalho da discussão da filosofia, não... “é um juiz da área”, então...

Porém, apesar das inúmeras discussões sobre a lei que impõe a preservação dos vínculos familiares e o não desmembramento de grupos de irmãos e de autores que mostram a importância da manutenção desse vínculo, como Levisky (2005), Fonseca (2004) e Winnicott (1999), especialmente para aqueles que já perderam tanto ao longo desse doloroso processo, alguns adultos cuidadores 
manifestaram veemência em justificar a separação por “categorias distintas” dessas crianças e adolescentes em sexo e idade. Assim, o respeito à importância dos vínculos afetivos fica aquém das normas e preconceitos sociais.

A saída dos adolescentes do abrigo é outro aspecto não menos complexo, por envolver o destino de indivíduos que, até então, estavam sob os cuidados da instituição e que, de uma hora para outra, serão desligados. A falta de perspectiva fica evidente na fala de um dos diretores, que avalia o desligamento como o aspecto mais negativo de sua função, que, muitas vezes, não acontece como ele “deseja”. Constata-se, então, o quanto uma forma "engessada" de agir dificulta outras alternativas possíveis, principalmente quando se pensa na complexidade do significado da palavra 'desabrigar'.

Adulto Daniela, diretora da instituição Renascer:

No sentido de completar os dezoito anos e ter que sair do abrigo sem ter um nível de escolaridade que tu consiga arranjar um emprego pra que dê pra te sustentar, entendeu,...[...] Bom, eu acho que o Estado poderia ajudar nisso.[...] Em que sentido? ter uma parceria com o Demhab, sabe tipo assim, fazer eles terem acesso a casas, apartamentos, sei lá, mas isso assim, a longo prazo, tipo quando eles tiverem doze ou treze anos já irem preparando, não começar a preparar o adolescente com dezesseis, dezessete anos, um ano antes de sair, isto é muito traumático, sabe, que nem o que aconteceu com uma menina de dezessete anos, ela fez dezoito anos e a monitoria, pela monitoria, ela ficaria ali, entendeu? e por ela também, claro, mas daí a ........ tu tem que mostrar o desligamento, e aí como é que tu vai mostrar o desligamento pro pessoal que não quer, os funcionários não querem, tu sabe... pô, mas a guria tá conosco desde os dois anos de idade.
Além da complexidade em torno do tema do desligamento, a fala desse diretor realça a dificuldade da transitoriedade da medida. Como pensar em perspectivas de futuro a médio e longo prazo para um adolescente e, ao mesmo tempo, trabalhar em prol da transitoriedade?

São ambíguos os discursos sobre o desligamento de adolescentes, visto que cada parte o percebe sob diferentes perspectivas. Por um lado, observa-se uma preocupação em relação à manutenção do auxílio prestado pelo Estado; por outro, existe a questão do tempo de abrigamento, do "prazo” para “colocar o adolescente na rua”. Adicionalmente, a saída de uma criança ou adolescente é sentido pelas instituições como uma grande “cobrança”, uma imperiosa necessidade de 'mostrar serviço' para, muitas vezes, manter um determinado convênio ou ter seu trabalho positivamente avaliado.

Há ainda, a sugestão de um acompanhamento quando se desabriga um adolescente, mas não se tem muito claro como este deveria ser feito, nem por quem. O que parece existir é uma preocupação com o pós-abrigo, uma prática que não existe nas instituições pesquisadas.

Adulto Daniela, diretora da instituição Renascer:

Tipo assim, como é que se diz, ... nós tínhamos na FASE, mas era mais com... do Município quem fazia era os técnicos da FASC, que fazia esse trabalho, era com os egressos, então pra ver como é que tá, por exemplo, a menina desligada hoje daqui a seis meses, tu não vai procurar pra saber como é ela tá hoje, “ô fulaninha como é que tu tá?”, sabe?

Refletir sobre as políticas públicas voltadas para a infância e a adolescência desamparada, ou chamada de "em situação de vulnerabilidade social”, não é tarefa simples, uma vez que é amplo o leque de instâncias envolvidas nesse contexto - que envolve desde a política interna 
das instituições até a política macro e inclui todo um contexto marcado por injustiças, práticas arcaicas e desigualdades. Dessa forma, talvez não seja coerente responsabilizar apenas uma instância pelo sucesso ou fracasso do atendimento. Por outro lado, a realidade sugere que essa possibilidade pode ser um caminho para que se consiga, pelo menos, diminuir as angústias dos trabalhadores da área.

Adulto Mateus, monitor da instituição Recriar:

Então como o juiz, como as pessoas não conseguem resolver esse problema, como que não dão um ultimato para um cara desses (referindo-se ao padrasto de um adolescente abrigado) olha... como uma mãe não consegue se impor, pra ter o seu filho. Então, essas coisas que não são nossas, é um sistema todo, é um conjunto todo que atrapalha os processos das crianças.

Além dos tópicos explorados até aqui, vale ressaltar que, no que se refere à política de atendimento à criança e ao adolescente, essa é uma área ainda, "apesar das boas intenções” -, segundo o diretor da instituição Recriar, restrita, pois não há intercâmbio no trabalho, e o público e o privado não se articulam para produzir conhecimento. Em conseqüência, a falta de experiência das pessoas envolvidas com a gestão das políticas gera atrasos e conseqüências.

Um ponto adicional é destacado por um monitor da instituição Renascer e refere-se a uma profunda fragilidade, dada a falta de um projeto pedagógico que delimite como o trabalho deve ocorrer e o quanto esse trabalho acontece de forma "voluntariosa". Essa forma "voluntariosa", utilizada para expressar a maneira como os adolescentes são acolhidos, é um aspecto que parece ir além do sentimento do adulto para interferir diretamente na prática no acolhimento oferecido e, posteriormente, no momento de desabrigar o adolescente. Essa "voluntariedade” é, ainda, segundo relato, praticada por todos os adultos envolvidos dos monitores aos técnicos e diretores.

Adulto Luiz, monitor da instituição Renascer:

Em tudo, na própria repreensão que tu faz pras crianças e pros adolescentes que tu atende, não é, o que tu passa pra ele é muito voluntarioso, é muito do teu e nem sempre o que tu acredita é o melhor, é adequado.

Apesar dos avanços na lei, a política de atendimento ainda é muito frágil, e essa fragilidade é sentida pelas crianças e adolescentes abrigados. Um aspecto citado por adultos de ambas as instituições é a falta de capacitação do profissional que atua diretamente com o abrigado e a dos profissionais que estão no comando - que, muitas vezes, não possuem a experiência devida para trabalhar a questão macro da situação da abrigagem junto aos diversos órgãos públicos.

Disso se pode reafirmar que a falta de políticas adequadas e a fragilidade do modelo vigente exercem uma significativa influência no atendimento oferecido às crianças e aos adolescentes. A análise aponta uma constatação acerca do desafio de definir políticas públicas na área da abrigagem, especialmente no que se refere à produção de uma prática distinta das vigentes, e a transformação de uma cultura ainda fundada em um modelo institucional repleto de estigmas, como o da situação irregular. Além disso, faz-se urgente adotar uma postura de maior clareza referente às definições de papéis, funções e valores das instituições, pois só então a sociedade, através das instituições, poderá cumprir uma função organizadora (Levisky, 2005). Do contrário, continuaremos a observar a triste situação de crianças e adolescentes tornando-se agentes e vítimas desse processo. 


\section{Análise}

Face à complexidade dos processos de abrigamento e das inúmeras histórias de vida alteradas com tal decisão judicial, refletir sobre o abrigo de adolescentes implica, antes de tudo, poder escutar as vozes desses jovens e compreender o quanto de sofrimento e angústia atravessam suas vidas; é reconhecer e entender os sérios prejuízos advindos dessa prática, que resulta, muitas vezes, em

A pobreza extrema é uma condição que submete inúmeras familias ao enquadramento nas vulnerabilidades sociais, impedindo pais de exercerem suas funções estruturantes, não por comprometimento interno, mas antes por uma situação externa extremamente desfovorável. segregação. Das vozes dos adolescentes e dos adultos cuidadores ecoam histórias, sonhos, desejos e uma realidade em constante processo de (trans)formação.

Sem a pretensão de delimitar modos de fazer, as autoras pretendem apresentar elementos acerca dos processos de estruturação dos abrigos para o acolhimento de crianças e adolescentes, com o intuito de nortear profissionais comprometidos com essa questão e que desejem proporcionar aos abrigados a garantia dos seus direitos.

Uma das questões que perpassa e interfere intimamente o processo de abrigo é a questão das políticas públicas voltadas para a infância e para a juventude. De acordo com inúmeros teóricos, dentre eles Sposito (2003), Abramo (1997) e Pais (1993), a ausência de maior envolvimento do governo federal e estadual para com a população juvenil e sua família contribui sobremaneira para a acentuada cronificação de um processo histórico de abandono e, em conseqüência, de institucionalização da pobreza.

O desmantelamento das grandes instituições, com o objetivo de proporcionar um acolhimento mais humanizado às crianças e adolescentes, faz vislumbrar novos modelos de abrigamento, nos quais a criança e o adolescente possam ser acolhidos em suas reais necessidades. Um dos objetivos desta pesquisa foi contribuir para ampliar a compreensão desse novo modelo e oferecer subsídios para o que Delgado (2000) reputa como a até então ausente produção de conhecimento dos seus efeitos nos abrigados.

Muitas são as interfaces que permeiam esse processo histórico de cronificação da pobreza, em que a questão econômica emerge como um dos mais nocivos vetores. Embora se saiba que a pobreza em si não deveria ser a causa do abrigamento de uma criança ou adolescente como preconizado pelo ECA, nos inúmeros casos de abrigo em que a justificativa é a pobreza, constata-se uma situação de miséria - crescente e avassaladora - que interfere diretamente na dinâmica das relações familiares e gera as denominadas "famílias desestruturadas”, um termo que identifica "famílias incapazes de cuidar dos filhos".

A pobreza extrema é uma condição que submete inúmeras famílias ao enquadramento nas vulnerabilidades sociais, impedindo pais de exercerem suas funções estruturantes, não por comprometimento interno, mas antes por uma situação externa extremamente desfavorável. Diante disso, acredita-se ser imprescindível estabelecer uma interlocução entre uma sociedade injusta que produziu essa exclusão e suas famílias excluídas, que parecem ter desistido do cuidado de seus filhos "devolvendo-os" ao Estado. Como resposta à "entrega dos filhos”, essas famílias são culpabilizadas ou vitimadas.

Ainda no que tange às políticas públicas, a revisão do modelo de abrigagem envolveu instâncias diferentes de responsabilidades e atribuições (Milnitsky-Sapiro, 2005), fazendo com que a Federação incumba os Municípios de administrar e manter as instituições. Conhecida como "municipalização", essa medida tem sido vista como positiva pelo fato de possibilitar que crianças e adolescentes sejam abrigados em uma instituição em seus Municípios de origem, visando a manter a proximidade com sua família. Por outro lado, profissionais dessas instituições 
freqüentemente denunciam o crescente abandono por parte do Estado, que simplesmente transferiu para o Município a responsabilidade de execução da medida de abrigagem.

Em conseqüência, uma estrutura falida e desmantelada vem dar, como resposta, o abrigamento - processo e produto da injustiça social, e, por causa do abrigamento, de acordo com características culturais e organizacionais de cada instituição, crianças e adolescentes muitas vezes experienciam situações e conflitos - que variam desde a ausência de um projeto pedagógico até o desligamento do adolescente da instituição como forma de garantir a transitoriedade da medida - tão contundentes quanto os que levaram à necessidade de uma medida de proteção.

A qualidade do acolhimento oferecido pelos abrigos, com freqüência, é prejudicada pela ambigüidade do conceito de transitoriedade, advindo da determinação do ECA de que a medida de abrigo é "provisória e excepcional”. O que se constata, muitas vezes, é que, por envolver aspectos complexos e sutis de uma prática institucional, a transitoriedade é dúbia tanto para quem trabalha nos abrigos quanto para as famílias e os adolescentes abrigados.

Antes de aprofundar essas considerações sobre transitoriedade, faz-se necessário o questionamento sobre " $a$ real função de um abrigo", já que a resposta dada pelo Estado a essa questão tem, comumente, justificado a prática institucional que referenda a transitoriedade. Diversas são as instâncias que permeiam a justificativa para a efetivação dessa transitoriedade, e a mais eloqüente é a que versa sobre as práticas do passado, nas quais a institucionalização massificada era indubitavelmente nociva.

Pode-se concluir, ainda, o quanto a cultura da transitoriedade dificulta o estabelecimento de vínculos entre adultos e adolescentes, já que os dois lados percebem "um tempo provisório" que os une, o que fragiliza a confiança e a dedicação recíprocas. O abrigo, então, acolhe o adolescente como se este estivesse em trânsito, o que invibiabiliza o reconhecimento de singularidades nos muitos que, infelizmente, não “estão só de passagem”.

É importante observar que, apesar do artigo 101, parágrafo único, do ECA versar sobre a transitoriedade da medida, anteriormente encontrava-se no artigo 92, inciso VI, a recomendação de "evitar, sempre que possível, a transferência para outras entidades de crianças e adolescentes abrigados”. Porém, o que se constata na prática é que a transitoriedade preconizada muitas vezes é utilizada para justificar a transferência entre instituições ou entre unidades de uma mesma instituição. No entanto, ao investigar as verdadeiras razões de uma transferência, é comum encontrar eventos de não obediência às “normas” da instituição. Pode ainda ser a prática da transitoriedade justificada através da transferência entre unidades da instituição com o objetivo de cumprir a determinação de diretrizes institucionais - para garantir os parâmetros de separação por idade e gênero.

Segundo os adultos, muitas vezes é inviável propor um trabalho pautado em termos de perspectivas de futuro com os adolescentes, uma vez que a provisoriedade pode atravessarlhes a vida a qualquer momento. Talvez seja a hora de, no que tange à questão da transitoriedade da medida, encontrar um meio termo entre a crueldade de um abrigo “definitivo" - implementado pelas grandes instituições massificadas do passado - e um abrigo muitas vezes volátil e descartável, implementado por diversas instituições do presente: um abrigo pautado por um plano de futuro para os abrigados e preocupado também com a continuidade do acolhimento oferecido (Winnicott (2002), Levisky (2005), 
Santos, (2004)). Constata-se, dessa forma, o quanto a transitoriedade interfere na prática cotidiana e no estabelecimento de um profícuo vínculo entre adultos cuidadores e adolescentes e ainda pode ser utilizada como explicação para a falta de compromisso da permanência do adolescente no abrigo e com o processo e a experiência com o cuidado.

Acredita-se ser imprescindível refletir acerca de outras possibilidades de acolhimento para crianças e adolescentes em situação de abandono distintas do modo de abrigo que se conhece até o momento. Uma certa prudência com a efetivação da transitoriedade também deve ser contemplada, pois verificase que, em muitos casos, essa medida é indiscriminadamente aplicada, simplesmente para números promissores aparecerem nas estatísticas sobre o abrigamento. Um outro modelo pode nascer quando os receios das institucionalizações massificadas abrirem espaço para levar em consideração que, algumas vezes, o abrigo é a última opção para inúmeras crianças e adolescentes que não estão em trânsito e que têm o direito de ser bem acolhidos. E, se isso se der junto a um familiar, tanto melhor.

Normalmente, a medida de abrigo tem o seu fim no momento do desligamento de um adolescente. As normas institucionais precisam ser revisadas por seus atores na medida em que priorizam “o desligamento” como elemento principal da institucionalização. Mesmo quando - e isso é o que infelizmente acontece, na grande maioria das vezes - os adolescentes não possuem um lugar para ir e deverão deixar para trás, mais uma vez, uma vida, uma história - que muitas vezes já estava sendo (a duras penas) ressignificada. Por outro lado, constatou-se também, nesta pesquisa, que os profissionais encarregados do processo de desligamento freqüentemente experienciam dúvidas e angústias em relação a como as decisões institucionais poderão afetar as vidas dos “jovens desligados”.

A falta de perspectiva para o adolescente que completa os dezoito anos é apontada como um dos principais aspectos ansiogênicos para os adultos cuidadores. Porém, o que parece não ser levado em consideração, quando se reporta ao futuro, são as experiências do passado e a sempre presente constatação de um contexto social carregado de depreciação, injustiças e falta de oportunidades para os jovens; especialmente para os jovens das classes menos favorecidas.

Uma das sugestões oferecidas por alguns técnicos para esse dilema é uma forma de continuação do atendimento através de parcerias com outras secretarias - como o Demhab, por exemplo - nas quais se poderia tentar garantir a continuação do trabalho.

É imperativo que se adote uma postura de maior clareza frente às definições de papéis, funções e valores de instituições de abrigo, pois só então a sociedade, através dessas instituições, poderá cumprir uma função realmente organizadora (LEVISKY, 2005). Do contrário, continuaremos a observar a triste situação de crianças e adolescentes como agentes e vítimas desse processo. Para alcançar essa meta básica, um ponto é fundamental - existência de uma “metodologia que respeite a importância dos vínculos afetivos e não apenas faça uso de um discurso de aparência e conveniências, mas que conduza a um encontro sincero, realista e de esperança...”(Levisky, 2005). 
Ana Paula Granzotto de Oliveira Psicóloga, pesquisadora do Núcleo CONVIVA, Mestre em Psicologia Social e InstitucionalPPG-UFRGS

Clary Milnitsky-Sapiro Instituto de Psicologia/UFRGS, PHD

Rua Costa Lima, n. 790, ap. 503, Teresópolis, Porto Alegre-RS CEP: 91.720-480 Telefones para contato: (51) 32419714 ou (51) 91765976

E-mail:anapaulagranzotto@gmail.com

\section{BRASIL, Estatuto da Criança e do Adolescente: Lei nº 8.069/1990.}

CARREIRÃO, Úrsula Lehmkuhl. Modalidades de abrigo e a busca pelo direito à convivência familiar e comunitária. In: SILVA, Enid Rocha Andrade (Org). $\mathbf{O}$ direito à convivência familiar e comunitária: os abrigos para crianças e adolescentes no Brasil. Brasília: IPEA CONANDA, 2004. 416p. cap. 11, p. 303 - 323.

DELGADO, P.G.G. Perspectivas da psiquiatria pós-asilar no Brasil (com um apêndice sobre a questão dos cronificados). In: TUNDIS, S. A.; COSTA, N. R.(Orgs.). Cidadania e loucura: políticas de Saúde Mental no Brasil. 6a ed. Petrópolis:Vozes, 2000. cap. 5, p.171 - 202.

FONSECA, C. Os direitos da criança - dialogando com o ECA. In: FONSECA, C.; TERTO JUNIOR, V.; ALVES, C. F.(Orgs.). Antropologia, diversidade e direitos humanos: diálogos interdisciplinares. Porto Alegre: Editora da UFRGS, 2004. cap. 1, parte II, p.103 - 115.

LEVISKY, David Léo. Trauma e adolescência. $44^{\circ}$ Congresso Internacional de Psicanálise. Rio de Janeiro: IPA, 2005.

MILNITSKY-SAPIRO, C. Construção de valores sócio-morais na cultura e suas formas de discriminação da adolescência. Simpósio Internacional do Adolescente. São Paulo, 1, 2005. Scielo Proceedings online.

OLIVEIRA, A. P. G. e MILNITSKY-SAPIRO, C. O ambiente de abrigo como holding para adolescentes. Simpósio Internacional do Adolescente. São Paulo, 2006. Scielo Proceedings online.
Oliveira (2001, p.70). Secretaria de Economia e Planejamento. Fundação Sistema Estadual de Análise de Dados - SEADE. Vinte anos no ano 2000: estudos sociodemográficos sobre a juventude paulista. São Paulo: SEADE, 1998

RIZZINI, I.; RIZZINI, I.“Menores” institucionalizados e meninos de rua. In: O trabalho e a rua: crianças e adolescentes no Brasil urbano dos anos 80. 2a ed. São Paulo: Cortez, 1996. cap. 3, p. 69 - 90

SANTOS, M. M. S. As angústias impensáveis e o manejo técnico na clínica - um estudo de caso. In: OUTEIRAL, J. (Org.). Winnicott: seminários brasileiros. Rio de Janeiro: Revinter, 2004. cap. 52, p. 420 - 428.

SPOSITO, M. P.; C. P. Juventude e políticas públicas no Brasil. Políticas Públicas de Juventud en América Latina, Viña Del Mar, Chile, p. 1 23, 2003

SPOSITO, M. P. Trajetórias na construção de políticas públicas de juventude no Brasil. In: PAPA, Fernanda de Carvalho (Org.). Políticas públicas: juventude em pauta. São Paulo: Cortez: Ação Educativa Assessoria, pesquisa e informação. Fundação Friedrich, 2003, p. 57-75.

WINNICOTT, D. W. Privação e delinqüência. Trad. Álvaro Cabral; ver. Mônica Stahel. - $3^{\text {a }}$ ed. São Paulo: Martins Fontes, 1999. 319. Título original: Deprivation and delinquency.
Referências 